\title{
Lipid Membrane Association of Myelin Proteins and Peptide Segments \\ Studied by Oriented and Synchrotron Radiation Circular Dichroism
}

\section{Spectroscopy}

Gopinath Muruganandam ${ }^{1}$, Jochen Bürck ${ }^{2}$, Anne S. Ulrich ${ }^{2}$, Inari Kursula ${ }^{1,3}$, Petri Kursula ${ }^{1,3,4,5}$

${ }^{I}$ Centre for Structural Systems Biology, Helmholtz Centre for Infection Research (CSSB-HZI),

German Electron Synchrotron (DESY), Hamburg, Germany

${ }^{2}$ Institute for Biological Interfaces 2 (IBG-2), Karlsruhe Institute for Technology (KIT), PO Box 3640, 76021 Karlsruhe, Germany

${ }^{3}$ Department of Biochemistry, University of Oulu, Oulu, Finland

${ }^{4}$ Biocenter Oulu, University of Oulu, Oulu, Finland

${ }^{5}$ Departmen of Chemistry, University of Hamburg, Hamburg, Germany

\section{Address for correspondence}

Petri Kursula, Department of Biochemistry \& Biocenter Oulu, University of Oulu, Oulu, Finland; email petri.kursula@oulu.fi 


\section{Abstract}

Myelin-specific proteins are either integral or peripheral membrane proteins that, in complex with lipids, constitute a multilayered proteolipid membrane system, the myelin sheath. The myelin sheath surrounds the axons of nerves and enables rapid transduction of axonal impulses. Myelin proteins interact intimately with the lipid bilayer and play crucial roles in the assembly, function, and stability of the myelin sheath. Although myelin proteins have been investigated for decades, their structural properties upon membrane surface binding are still largely unknown. In this study, we have used simplified model systems consisting of synthetic peptides and membrane mimics, such as detergent micelles and/or lipid vesicles, to probe the conformation of peptides using synchrotron radiation circular dichroism spectroscopy (SRCD). Additionally, oriented circular dichroism spectroscopy (OCD) was employed to examine the orientation of myelin peptides in macroscopically aligned lipid bilayers. Various representative peptides from the myelin basic protein (MBP), P0, myelin/ oligodencrocyte glycoprotein, and connexin32 (cx32) were studied. A helical peptide from the central immunodominant epitope of MBP showed a highly tilted orientation with respect to the membrane surface, whereas the N-terminal cytoplasmic segment of cx32 folded into a helical structure that was only slightly tilted. The folding of full-length myelin basic protein was, furthermore, studied in a bicelle environment. Our results provide information on the conformation and membrane alignment of important membrane-binding peptides in a membrane-mimicking environment, giving novel insights into the mechanisms of membrane binding and stacking by myelin proteins.

\section{Keywords}

myelin, peripheral membrane protein, synchrotron circular dichroism, spectroscopy, helix orientation, lipid-induced folding 


\section{Introduction}

The myelin sheath is an insulating multilayered membrane tightly wrapped around neuronal axons in both the central and peripheral nervous systems (CNS and PNS, respectively). It facilitates the rapid saltatory conduction of nerve impulses along the axons in vertebrates, a process that is essential for proper functioning of the nervous system. Demyelination, that destroys the myelin sheath, leads to failed nerve conduction and neurodegeneration. Myelin consists of $80 \%$ lipids and $20 \%$ proteins by dry weight, and a very small amount of aqueous solvent. Myelin-specific proteins are mainly integral or peripheral membrane proteins that interact intimately with lipid bilayers ${ }^{1,2}$. The major myelin proteins are unique to the myelin sheath, as evidenced by their remarkably low levels of expression in other tissues. The myelin sheaths in the CNS and PNS differ biochemically, mainly due to their unique protein compositions.

Many of the soluble myelin proteins become peripherally attached to membrane surfaces, and also the cytoplasmic domains of integral myelin membrane proteins are likely to contain membrane-associating segments. These properties are important for the function of myelin proteins in bringing apposing lipid membrane surfaces tightly together, after the membrane has wrapped dozens of times around the myelinated axon.

Various membrane-mimicking environments coupled to spectroscopic methods can be used as simplified systems for characterizing conformational changes in membrane-active peptides and peripheral membrane proteins upon membrane binding. Such environments include, for example, organic solvents, detergent micelles, detergent/phospholipid bicelles, lipid vesicles, and oriented membranes. In the simplest case, one can examine the conformation of peptides in trifluoroethanol (TFE) using conventional circular dichroism spectroscopy (CD), while advanced techniques, like oriented circular dichroism (OCD), can reveal the orientation of peptides with respect to the bilayer surface. In the case of myelin proteins, specifically the 
myelin basic protein (MBP), various other methods have also been used to obtain information on protein-membrane interactions and lipid-induced folding of the protein ${ }^{3-7}$.

OCD is a useful method for determining of the orientation of secondary structure elements in macroscopically oriented samples. OCD has mostly been used to estimate the alignment of helical membrane-active peptides in oriented lipid bilayers ${ }^{8-16}$, and this is also where the theoretical basis for spectral analysis is at its strongest ${ }^{12,16}$. Distinct lineshapes characterize the OCD spectra from helices with different orientations with respect to the incident light beam, so surface-bound helices and transmembrane segments are easily recognized. Limited literature also exists on the use of OCD for studying larger $\alpha$-helical proteins ${ }^{17,}{ }^{18}$ and peptides with $\beta$ structures ${ }^{19,20}$. Recently, we used OCD to study membrane binding by the myelin protein $\mathrm{P} 2{ }^{21}$.

Here, we have investigated the conformations of selected membrane-binding segments from various myelin proteins in different membrane-mimicking environments, including detergent micelles of dodecyl phosphocholine (DPC) and sodium dodecylsulphate (SDS), as well as lipid vesicles of dimyristoyl phosphatidylcholine (DMPC) and dimyristoyl phosphatidylglycerol (DMPG). In a previous study, we reported the conformation of peptides from selected myelin proteins in the presence of TFE and micelles, such as DPC and dodecyl dimethylamine oxide (DDAO) ${ }^{22}$. In our current study, we have also employed lipid vesicles, since a lipid bilayer can mimic a cellular membrane much better than small, highly curved detergent micelles. In addition to the conformations of the membrane-bound peptides from SRCD, our results from OCD spectroscopy also reveal a concentration-dependent realignment of some of the peptides in oriented phospholipid multilayers. Furthermore, we provide high-quality SRCD data on a system that is notoriously difficult for spectroscopic measurements: the full-length MBP bound to lipid bilayers. 


\section{Experimental methods}

\section{Materials}

Synthetic peptides corresponding to putative membrane-binding regions of myelin-specific proteins were chosen using available information from scientific literature, sequence-based prediction of secondary structure, and the prediction of amphipathic helices with Amphipaseek ${ }^{23}$. The peptides were purchased from SBS Genetech (Beijing, China) and dissolved at a concentration of $10 \mathrm{mg} / \mathrm{ml}$ either in $10 \mathrm{mM}$ potassium phosphate $(\mathrm{pH} 7)$ or in degassed distilled water. The concentration used was based on the information from the manufacturer. The $\mathrm{N}$ and $\mathrm{C}$ termini of the peptides were acylated and amidated respectively, unless stated otherwise. Recombinant mouse 18.5-kDa MBP isoform with a C-terminal Histag was expressed in E. coli and purified as previously described ${ }^{24,25}$.

DPC was purchased from Anatrace (Maumee, OH, USA). Dimyristoyl-phosphatidic acid (DMPA), DMPC and DMPG were purchased from Larodan Fine Chemicals (Malmö, Sweden) or Avanti Polar Lipids (Alabaster, AL, USA). Bicelles were prepared by mixing DPC with either DMPC or DMPA in a molar ratio of 1:4.

DMPC and DMPG were used to prepare liposomes. The lipids were separately dissolved in 1:1 (v:v) chloroform/methanol to get individual lipid stock solutions of $7.3 \mathrm{mM}$. Aliquots of the stock solutions were combined and vortexed to obtain a DMPC/DMPG 1:1 molar mixture. Subsequently, organic solvents were removed under a gentle stream of nitrogen, followed by 4-5 $\mathrm{h}$ in a vacuum. The thin DMPC/DMPG lipid film was dispersed in $10 \mathrm{mM}$ potassium phosphate ( $\mathrm{pH}$ 7), and the lipid dispersion was homogenized and hydrated by vigorous vortexing for $7 \times 1 \mathrm{~min}$, and by performing 7 freeze-thaw cycles resulting in multilamellar vesicles (MLVs). Small unilamellar vesicles (SUVs) were generated by 
sonication of the MLVs for 3x4 min in a strong ultrasonic bath (UTR 200, Hielscher, Germany), avoiding overheating of the samples.

Synchrotron radiation circular dichroism spectroscopy

SRCD spectra for the peptide samples were recorded on the UV-CD12 beamline at the ANKA synchrotron facility in Karlsruhe, Germany. Three spectra were collected at a scan rate of $14 \mathrm{~nm} / \mathrm{min}$ and a bandwidth of $1 \mathrm{~nm}$ at $0.5-\mathrm{nm}$ intervals either in a demountable 13$\mu \mathrm{m} \mathrm{CaF}_{2}$ cuvette $(1 \%$ detergents, $9 \mathrm{mg} / \mathrm{ml}$ peptide) or in a cylindrical $100-\mu \mathrm{m}$ quartz glass cuvette (all others, $1 \mathrm{mg} / \mathrm{ml}$ peptide) between 260 and $170 \mathrm{~nm}$ and averaged, and the spectrum measured from the corresponding buffer was subtracted. The data were analyzed and processed using CDtool ${ }^{26}$.

The spectra for samples of full-length MBP were collected on the CD1 beamline on the ASTRID storage ring at ISA, Aarhus, Denmark. $100-\mu \mathrm{m}$ quartz glass cuvettes were used, and the protein concentration was between $0.62-0.70 \mathrm{mg} / \mathrm{ml}$. Spectra were measured from 280 to $170 \mathrm{~nm}$, and 3 consecutive scans were averaged and buffer-subtracted prior to analysis. The tested conditions included bicelles of DMPC/DPC and DMPA/DPC, salt (NaF), and molecular crowding (4\% PEG 20000). Temperature scans for MBP in bicelles were also carried out in the same sample cell.

Secondary structure deconvolution for the SRCD spectra was carried out using a leastsquares fitting protocol in Microsoft Excel, utilizing the theoretical CD spectra for helix, strand, and coiled structure ${ }^{27}$. The method was based purely on the shape of the curves between $190-250 \mathrm{~nm}$, as the signal from our samples varied due to limited solubility and light scattering from peptide-lipid complexes in several samples. Hence, the results should be taken as semi-quantitative between different peptides, but suitable for comparison of behaviour under different conditions. As a control, the calmodulin SRCD spectrum from the 
Protein Circular Dichroism Data Bank ${ }^{28}$ was analysed and found to yield nearly identical secondary structure content to the crystal structure. More complicated methods are generally well suitable for full-length folded proteins, but not necessarily for peptides ${ }^{29}$ and/or proteins having mainly a disordered structure, especially if solubility is an issue.

\section{Conventional and oriented circular dichroism spectroscopy}

The peptides were added to the unilamellar DMPC/DMPG (1:1) vesicles at calculated molar protein:lipid $(\mathrm{P} / \mathrm{L})$ ratios of 1:30 and 1:100. Upon mixing the peptides with the vesicles, the samples were sonicated again to avoid any potential aggregation. Thereafter, conventional isotropic CD spectra of the suspensions were collected on a J-815 spectropolarimeter (JASCO). Measurements were performed in a 1-mm quartz glass cell (Suprasil, Hellma) between 260 and $185 \mathrm{~nm}$ at $0.1-\mathrm{nm}$ intervals. Spectra were recorded at $+30^{\circ} \mathrm{C}$, i.e. above the phase transition temperature of the lipids. Three scans at a scan-rate of $10 \mathrm{~nm} / \mathrm{min}, 8 \mathrm{~s}$ response time, and $1 \mathrm{~nm}$ bandwidth were averaged for each sample and baseline, and the baseline was subtracted from the sample spectrum. Mean residue ellipticities (MRE) were then calculated based on the peptide concentrations.

For OCD in DMPC/DMPG 1:1 bilayers, $200 \mu 1$ of the peptide/lipid SUVs were deposited as a spot of $\sim 12 \mathrm{~mm}$ diameter on a UV-transparent quartz glass plate (Suprasil QS, Hellma Optik GmbH, Jena, Germany), and water was evaporated under a gentle stream of air. The 1:100 sample contained approximately $5 \mu \mathrm{g}$ peptide and $160 \mu \mathrm{g}$ lipid. The quartz glass window with the dried sample was assembled with a second clean window in the OCD sample cell. During rehydration, the lipids spontaneously align as macroscopically oriented lipid bilayers on the glass surface. The sample was dried and then hydrated via the gas phase in the OCD chamber containing a saturated $\mathrm{K}_{2} \mathrm{SO}_{4}$ solution for $15 \mathrm{~h}$ at $+30^{\circ} \mathrm{C}$, and measured immediately after preparation. 
OCD data were collected on a Jasco J-810 spectropolarimeter with a home-built sample holder. This OCD cell is controlled by a computer and can be integrated to the J-810 spectropolarimeter ${ }^{8}$, allowing measurements under controlled humidity (97\%) and temperature $\left(+30^{\circ} \mathrm{C}\right)$. OCD spectra were collected between 260 and $180 \mathrm{~nm}$ at $0.1-\mathrm{nm}$ intervals. The spectra were recorded at eight different sample rotation angles about the beam axis ${ }^{30}$ and averaged to correct for any spectral artifacts caused by linear dichroism and birefringence. Spectra from pure lipid bilayers were measured similarly and subtracted from those of the peptide-containing samples. Data were processed as previously described ${ }^{8}$. 


\section{Results}

SRCD spectra of myelin peptides under membrane-mimicking conditions

The peptides used in the study were chosen from different myelin proteins present in the CNS and/or PNS (Figure 1). For target selection, properties such as secondary structure, propensity to fold into amphipathic helices, and disordered regions were predicted from the peptide sequence and taken into account (data not shown). The details of the chosen peptides are given in Table 1, and helical wheel projections are shown in Supplementary Figure 1. The peptides MBP2 and MBP3 were used in our earlier studies, in which we analyzed the interaction of MBP with calmodulin ${ }^{31,32}$. The peptides from P0 and MOG were also used in a more recent study to monitor peptide folding in other membrane-mimicking conditions ${ }^{22}$.

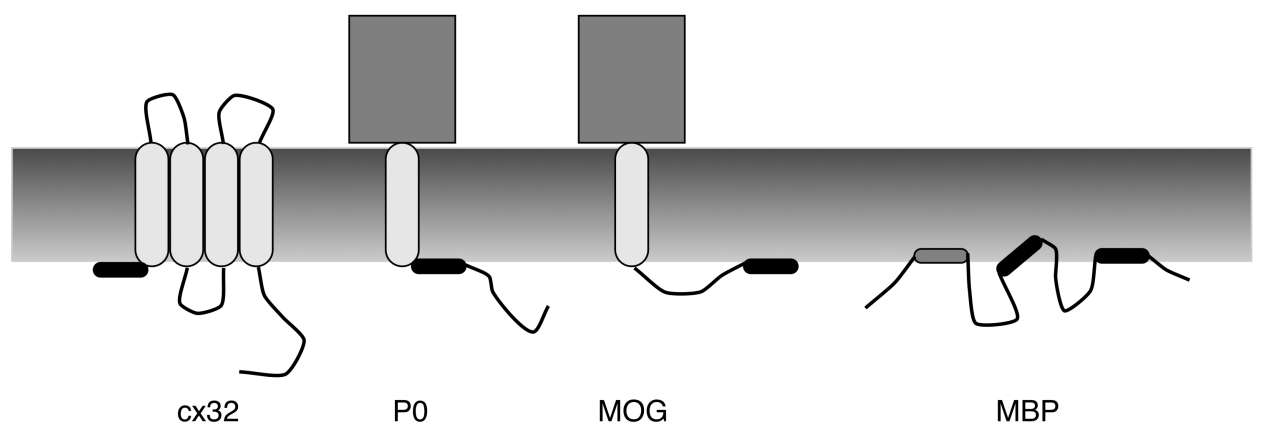

Figure 1. Schematic representation of the locations of the selected peptides in myelin proteins bound to the membrane. The peptides from the current study are indicated in black.

\section{Table 1. Peptides used in the current study}

The phosphorylation (P) and palmitoylation (pal) sites and unmodified C-termini $(\mathrm{COOH})$ are indicated where applicable. All sequences correspond to those of human proteins, except MBP3 and MBP9p, which correspond to the MBP2 peptide segment in the mouse sequence. The mean hydrophobicity of peptides was calculated using HydroMCalc (http:/ 
/www.bbcm.univ.trieste.it/ tossi/HydroCalc/HydroMCalc.html). Hydrophobic moments are as given by the helical wheel projection server (http://rzlab.ucr.edu/scripts/wheel/wheel.cgi). The values for the phosphopeptides (asterisks) were calculated by mimicking the phosphorylated residue with glutamate. The palmitoylation and end group modifications were not taken into account.

\begin{tabular}{|c|c|c|c|c|c|}
\hline peptide & sequence & residues & $\mid \begin{array}{ll}\text { net } & \text { charge } \\
\text { at } & \text { neutral } \\
\text { pH } & \end{array}$ & $\begin{array}{l}\text { mean } \\
\text { hydrophobicity }\end{array}$ & $\begin{array}{l}\text { hydrophobic } \\
\text { moment }\end{array}$ \\
\hline MBP1 & NPVVHFFKNIVTPR & $85-98$ & +3 & -0.07 & 3.3 \\
\hline MBP2 & $\begin{array}{l}\text { HKGFKGVDAQGT } \\
\text { LSKIFK }\end{array}$ & $139-156$ & +4 & -1.75 & 3.38 \\
\hline MBP3 & $\begin{array}{l}\text { HKGFKGAYDAQG } \\
\text { TLSKIFK }\end{array}$ & $136-154$ & +4 & -1.80 & 6.23 \\
\hline MBP8p & $\begin{array}{l}\text { NPVVHFFKNIVT(P) } \\
\text { PR }\end{array}$ & $\begin{array}{l}\text { phosphorylated } \\
\text { MBP1 }\end{array}$ & +2 & $-0.40^{*}$ & $5.18 *$ \\
\hline MBP9p & $\begin{array}{l}\text { HKGFKGAYDAQG } \\
\text { TLS(P)KIFK }\end{array}$ & $\begin{array}{l}\text { phosphorylated } \\
\text { MBP3 }\end{array}$ & +3 & $-2.01 *$ & $6.01 *$ \\
\hline P0 & $\begin{array}{l}\text { RYC(pal)WLRRQA } \\
\text { ALQRRL }\end{array}$ & $151-165$ & +5 & -1.68 & 2.32 \\
\hline MOG & $\begin{array}{l}\text { LHRTFGQFLEELR } \\
\text { NPF-COOH }\end{array}$ & $161-177$ & +1 & -0.05 & 7.89 \\
\hline $\operatorname{cx} 32$ & $\begin{array}{l}\text { MNWTGLYTLLSG } \\
\text { VNRHSTAIG }\end{array}$ & $1-21$ & +2 & 0.11 & 3.87 \\
\hline
\end{tabular}

SRCD spectra were measured from the peptides in the presence and absence of 0.1 and $1 \%$ DPC and SDS, as well as unilamellar lipid vesicles of DMPC/DMPG (1:1). The following standard conformation-derived features of the SRCD spectra were applied to compare the 
secondary structure contents of the peptides: a strong negative band at $200 \mathrm{~nm}$ for an unfolded peptide, the characteristic negative peaks at 208 and at $220 \mathrm{~nm}$ and a positive peak at $191-193 \mathrm{~nm}$ for an $\alpha$-helical peptide, and a broad negative peak around $218 \mathrm{~nm}$ for a $\beta$ stranded peptide (often indicative of aggregation). Specifically, the position of the peak between 200 and $208 \mathrm{~nm}$ allowed to directly follow folding/unfolding of helical structures. In addition, least-squares fitting to standard spectra was carried out for semi-quantitative analysis of secondary content.

As expected, the SRCD spectra of the peptides alone in phosphate buffer were dominated by the negative peak at $200 \mathrm{~nm}$, characteristic of predominantly random coil structures. Hence, in solution, the peptides did not fold into secondary structures. The use of membranous conditions, on the other hand, induced varying degrees of $\alpha$-helical conformation, as detailed below.

The MBP1 peptide from the myelin basic protein gained significant $\alpha$-helical structure in the presence of micelles of $0.1 \%$ SDS and vesicles of DMPC/DMPG (Figure 2A,F). 0.1\% DPC did not affect the conformation of the peptide much. Both 1\% DPC and SDS induced a high helical content.

The peptides MBP2 and MBP3 folded into $\alpha$-helical structures when mixed with DMPC/ DMPG vesicles (Figure 2B,C,F). However, there was no transition in the conformation of the peptides in the presence of SDS and DPC at $0.1 \%$. MBP2 was also tested with $1 \%$ detergents, and both of them gave spectra close to the membrane-bound conformation.

The peptide MBP8p, which is the phosphorylated form of MBP1, formed $\alpha$-helices in the presence of both $0.1 \%$ SDS and vesicles of DMPC/DMPG (1:1) (Figure 2D,F). 1\% DPC also induced helical folding, and 1\% SDS even more. Apparently, a negatively charged surface facilitates helix formation for both the phosphorylated and unmodified forms of this peptide. 
The helical content of the phosphorylated form in membrane-mimicking conditions was, however, systematically lower than for MBP1.

The MBP9p peptide, which is the phosphorylated version of MBP3, showed significant $\alpha$ helical conformation in complex with DMPC/DMPG vesicles (Figure 2E,F), as well as in 1\% detergents. This transition is similar to that observed in the non-phosphorylated MBP3 peptide bound to vesicles. Hence, phosphorylation had little effect on the behaviour of this segment. Since MBP3 was slightly insoluble and not used in all conditions, MBP9p can also be compared to the nearly identical MBP2 peptide; folding of the phosphorylated peptide seems impaired at the lowest detergent concentrations, but is not affected in the other samples (Figure 2F).

A

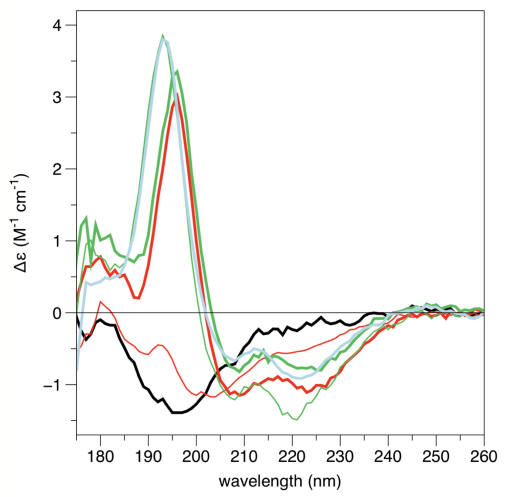

D

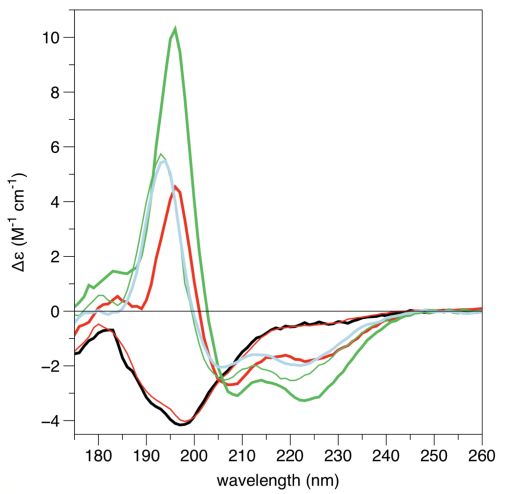

B

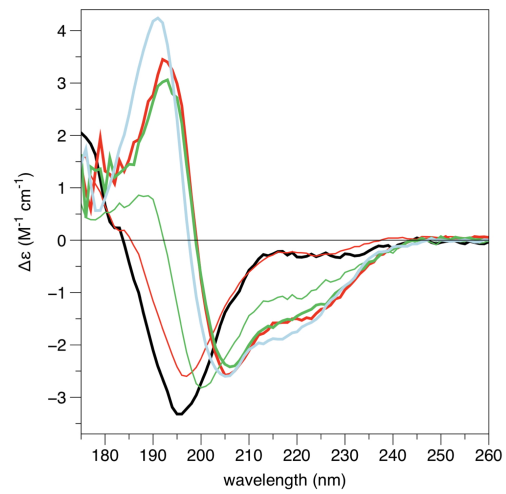

E

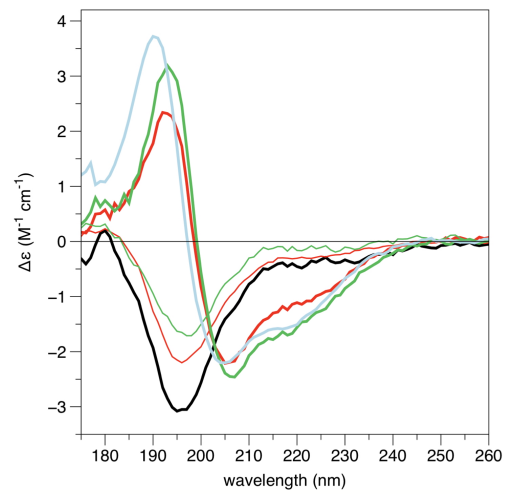

C

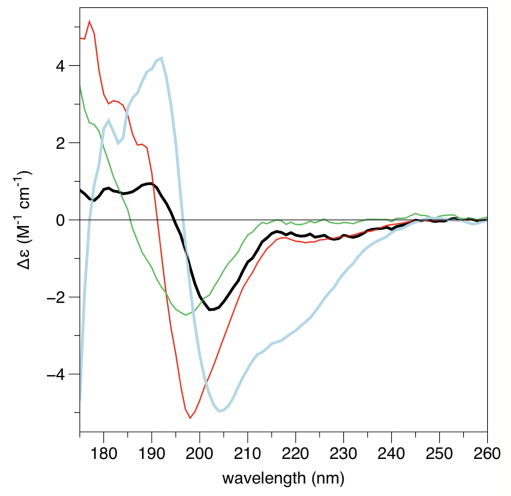

$\mathrm{F}$

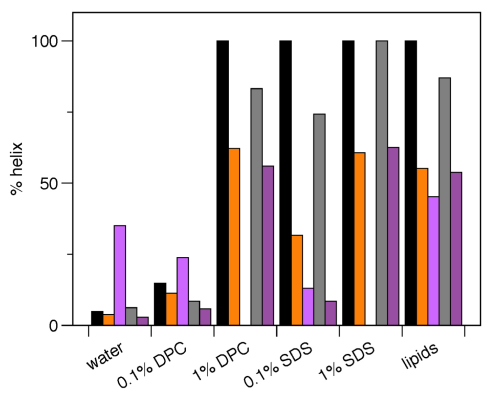

Figure 2. SRCD of peptides from MBP. Black, in buffer; blue, in DMPC/DMPG vesicles; red, with DPC (thin-0.1\%, thick-1\%); green, with SDS (thin-0.1\%, thick-1\%). A. MBP1. B. MBP2. 
C. MBP3. D. MBP8p. E. MBP9p. F. Estimated helical content of the MBP peptides in different conditins. MBP1-black, MBP2-orange, MBP3-pink, MBP8p-gray, MBP9p, magenta.

The peptides from the $\mathrm{P} 0$ juxtamembrane segment and the $\mathrm{C}$ terminus of one of the myelin/ oligodendrocyte glycoprotein (MOG) splice variants formed $\alpha$-helical structures in the DMPG/DMPC vesicles (Figure 3A,B,D). These peptides were, in fact, poorly soluble in aqueous solvents, but could be solubilized upon mixing with membranes - as previously observed for detergents ${ }^{22}$. These peptides were also measured in $0.1 \%$ DPC and SDS, showing that both detergents induced folding. For the P0 peptide, the spectra in membranes and micelles are similar, while for the MOG peptide, the spectra in detergents are much more intense. This indicates sub-optimal solubility of the MOG peptide even in the presence of lipid bilayers. It is likely that the five arginine residues in the P0-peptide and the two arginine residues in the MOG peptide interact with the phosphate headgroups and alter the conformation.

The SRCD spectra of the peptide from connexin 32 (cx32) indicate that the peptide easily formed $\alpha$-helical conformations under all the membrane-mimetic conditions applied (Figure $3 \mathrm{C}, \mathrm{D})$. This observation raises the possibility that this segment is actually not a cytoplasmic tail but a membrane anchor. 
A

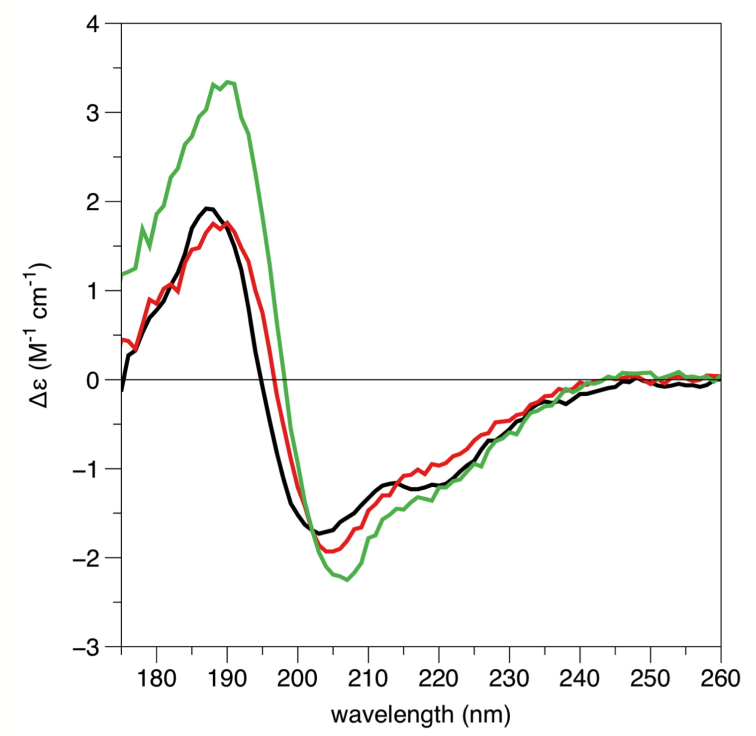

C

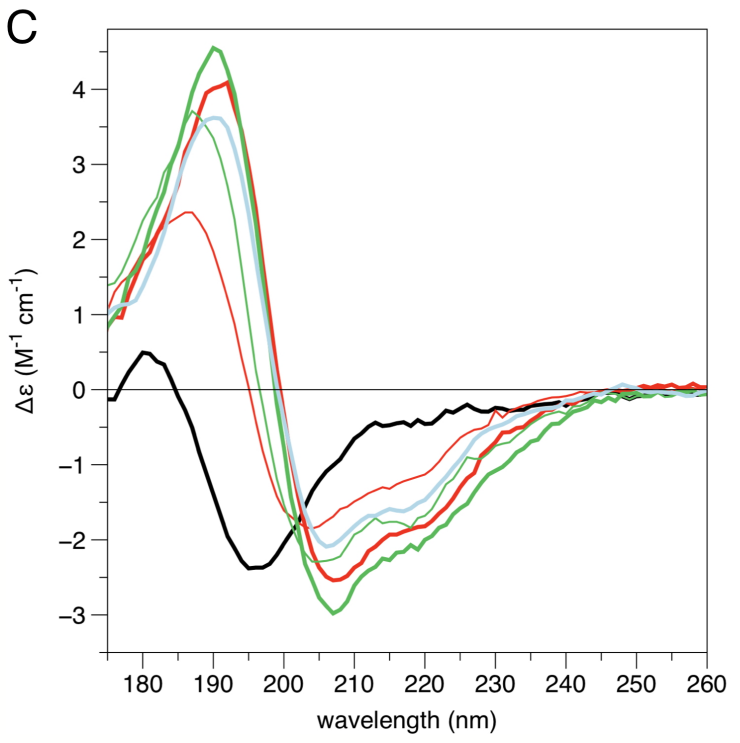

B

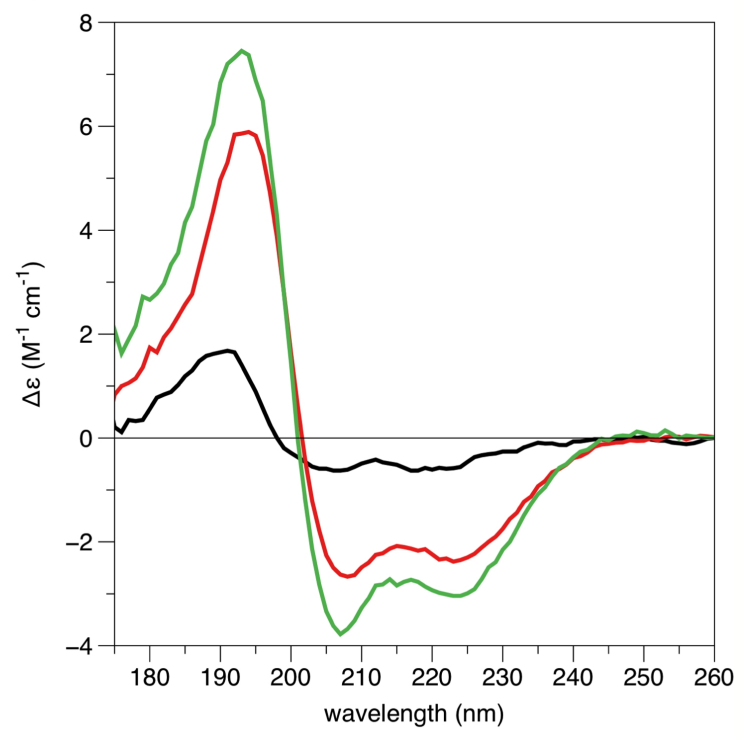

D

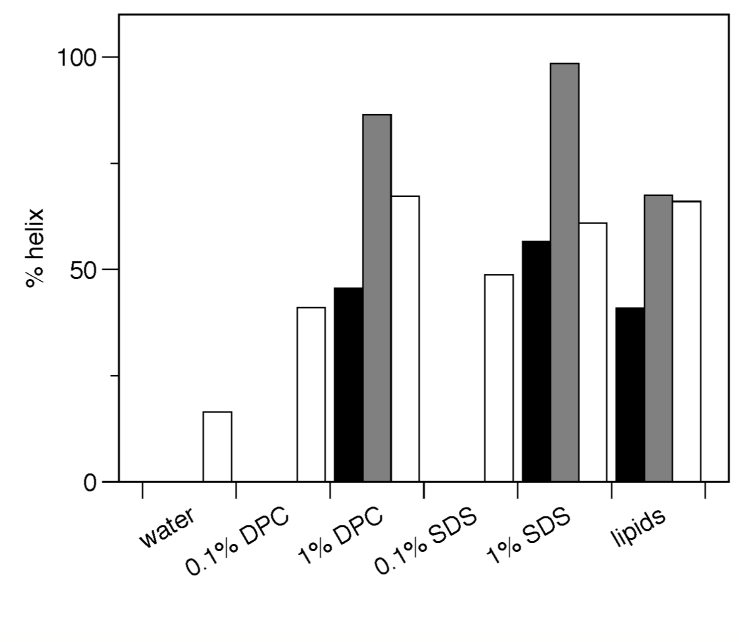

Figure 3. SRCD of peptides from other myelin proteins. A. PO and B. MOG peptides mixed with DMPC/DMPG vesicles (black), 1\% DPC (red), and 1\% SDS (green). C. The cx32 peptide under all tested conditions. Colours and linewidths as in Figure 2. D. Estimated helical content for the shown spectra (white-cx32, black-P0, gray-MOG).

As some of the peptides were not affected by $0.1 \%$ detegents, SRCD spectra were also measured at a higher peptide concentration in the presence of $1 \%$ DPC or SDS. In all cases, the peptide-micelle ratio was approximately 1:1. The results indicate a more efficient folding of the peptides at high detergent concentrations. This finding is slightly surprising, especially 
in the case of DPC, for which $0.1 \%$ already corresponds to twice the critical micellar concentration (CMC). It is conceivable that at least some of the peptides bind enough DPC at the lower concentration to bring the concentration of free DPC below the CMC. Conformational changes are, however, in these cases only detectable at higher DPC concentrations. For SDS, on the other hand, $\mathrm{CMC}$ is around $0.2 \%$; hence, the difference between concentrations can be justified by the complete lack of micelles at $0.1 \%$ SDS. In this respect, it is interesting to note that peptides MBP1 and MBP8p folded into a helical conformation already below the CMC in SDS. Taken together, future experiments using different peptide:micelle ratios with various detergents are warranted.

\section{Peptide orientation in membranes}

For the peptides showing a clear helical conformation in the SRCD spectra of vesicle-bound samples, further experiments were carried out to shed light on their respective orientations in the membrane. These experiments involved mixing of the peptides with SUVs at two different $\mathrm{P} / \mathrm{L}$ ratios and measuring both the isotropic and oriented $\mathrm{CD}$ spectra from each sample, using a conventional CD instrument fitted with a special OCD sample holder. It is possible that the peptide conformations are affected by the large surface curvature of SUVs; on the other hand, oriented planar multilayers were used in OCD.

For this experiment, the peptides from MBP, MOG, P0 and cx32 were mixed with lipid vesicles at two different peptide-to-lipid ratios (1:100 and 1:30). In accordance with the SRCD spectra above, all of the peptides showed helical structure in their respective isotropic CD spectra in the presence of lipid vesicles. To estimate the orientational tilt angle of the helices, OCD spectra were measured from the same samples after macroscopic orientation in the OCD cell. 
The basis of OCD for determining helix orientation lies in the theory of distinct spectra for a helix oriented parallel vs. perpendicular to the incoming light beam. A transmembrane helix in macroscopically oriented membranes has its axis along the beam and presents two bands in its spectrum; a minimum around $225 \mathrm{~nm}$ and a maximum at $195 \mathrm{~nm}$, while the negative 208$\mathrm{nm}$ fingerprint band is completely absent ${ }^{14,16}$. A helix parallel to the membrane surface will have minima at 208 and $225 \mathrm{~nm}$, with the 208-nm band more pronounced than the $225-\mathrm{nm}$ band, as well as a maximum around $190 \mathrm{~nm}^{14,16}$.

A general feature of OCD spectra of short peptides is that at low $\mathrm{P} / \mathrm{L}$ ratios, spectral intensities get small and the signal-to-noise ratio is poor. At higher $\mathrm{P} / \mathrm{L}$ ratios, the data can be better interpreted due to the stronger signal. Unfortunately, some of the peptides had a tendency to aggregate under OCD conditions, especially at the high peptide concentration $(\mathrm{P} /$ L 1:30). This aggregation leads to light scattering such that the light cannot reach the detector, leading to a very low intensity of the OCD signal. Another problem was that in some cases the helicity was relatively low, shifting the 208-nm helical "fingerprint" band for some of the peptides to shorter wavelengths $\sim 205 \mathrm{~nm}$.

The MBP1 peptide showed clear signs of a highly tilted helix, which was aligned almost in a transmembrane orientation (Figure 4A). This is evidenced by the strong peaks at 225 and 195 $\mathrm{nm}$, and the near lack of the $208-\mathrm{nm}$ band at $\mathrm{P} / \mathrm{L}$ ratio $1: 30$. At $\mathrm{P} / \mathrm{L}$ ratio $1: 100$, the $208-\mathrm{nm}$ peak is slightly more pronounced, suggesting a less tilted orientation (Figure 4A, inset). Crowding of the peptide on the membrane, hence, apparently causes higher tilting with respect to the membrane plane. The phosphorylated variant of MBP1 did not show this conformation, and it may also have a significant fraction of $\beta$-stranded secondary structure (Figure 4A). Of note, in molecular dynamics simulations, $\beta$ structure has been detected in this region upon phosphorylation ${ }^{33}$.

MBP2 formed $\beta$ structures at both concentrations in oriented membranes, as shown by the minimum at $215 \mathrm{~nm}$ and the maximum at $198 \mathrm{~nm}$. The peptide was helical prior to membrane 
orientation, and possibly was affected by the drying and rehydration of the oriented sample. In line with this observation, also peptides MBP3 and MBP9p showed signs of aggregation in OCD and were not analyzed in detail (data not shown).

The P0 juxtamembrane peptide OCD spectrum has a characteristic shape of a peptide lying as a helix parallel to the membrane surface. However, superposition with the isotropically measured spectrum in vesicles shows essentially identical spectra (Figure 4B). Possible explanations include (1) the peptide is indeed parallel to the membrane surface and the OCD spectrum is genuine, or (2) the membranes have failed to orient properly in the presence of this peptide, or (3) the peptide has a random orientation, even though the lipids are well oriented. Since this peptide is expected to anchor to the membrane mainly via its palmitoyl group, further studies will be required to confirm the peptide orientation.

The peptide from the MOG $\mathrm{C}$ terminus forms a $\beta$ structure/aggregate at $1: 100 \mathrm{P} / \mathrm{L}$, but at $\mathrm{P} / \mathrm{L}$ ratio 1:30, its OCD spectrum is indicative of a helix that is aligned in the membrane plane (Figure 4C). However, this spectrum could be affected also by a low helix content, as the minimum at $208 \mathrm{~nm}$ has shifted to $205 \mathrm{~nm}$. The isotropic sample, on the other hand, showed peak positions as expected for a helical structure. The helical wheel reconstruction of the sequence (see Supporting Information) strongly suggests the possibility of an amphipathic helix along the membrane surface.

The N-terminal segment of cx32 was clearly helical and in a tilted state in the OCD spectrum at $\mathrm{P} / \mathrm{L}$ ratio $1: 100$, while it aggregated at the higher peptide concentration (Figure $4 \mathrm{D}$ ). At $\mathrm{P} / \mathrm{L}$ ratio $1: 100$, the minimum at $221 \mathrm{~nm}$ is pronounced, as is the maximum at $193 \mathrm{~nm}$. The 208 $\mathrm{nm}$ band is clearly visible, but much diminished compared to the isotropic spectrum. Thus, the spectrum is mid-way between the typical helix orientations parallel and perpendicular to the membrane plane. 
A

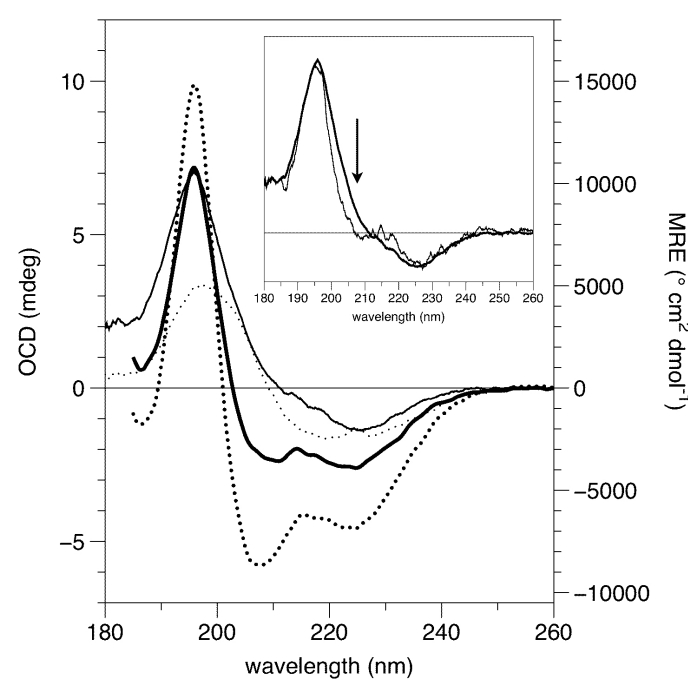

C

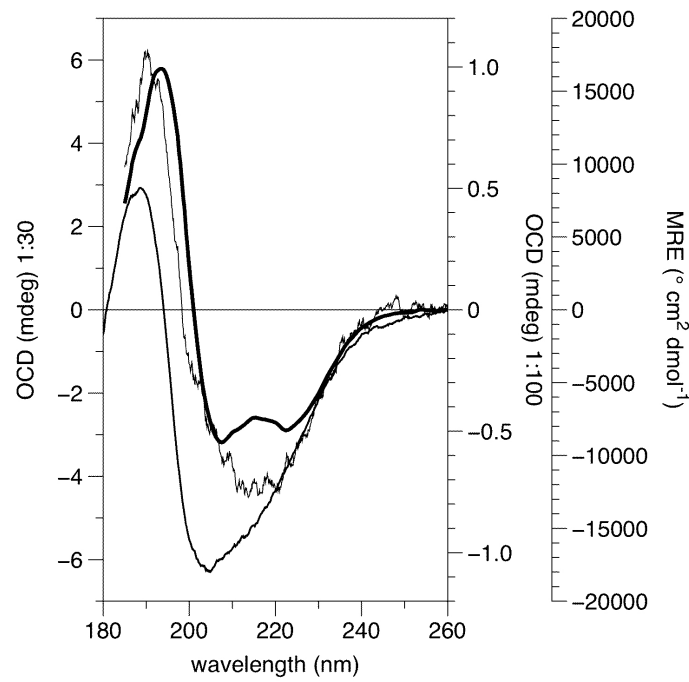

B

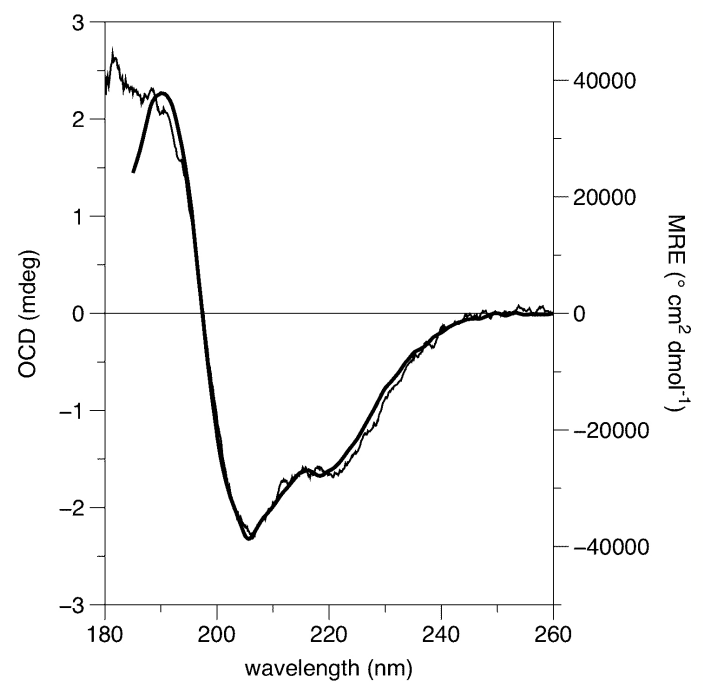

D

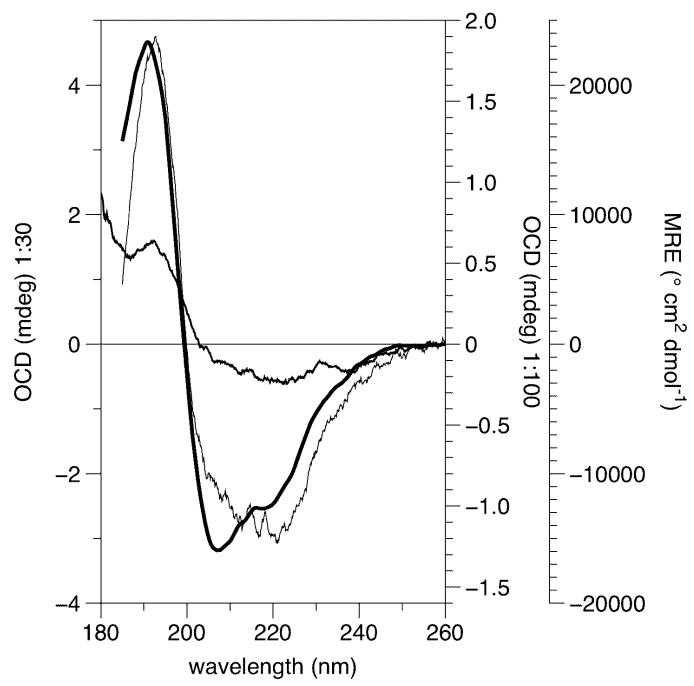

Figure 4. Comparison of isotropic and oriented CD spectra for myelin protein peptides. The isotropic samples contain vesicle-bound peptides, and the OCD samples are the same samples after macroscopic orientation. A. Peptides MBP1 (solid) and MBP8p (dotted). The thick line shows the isotropic spectrum and the thin line the OCD spectrum at P/L 1:30. The inset further shows $O C D$ spectra of MBP1 at P/L 1:30 (thick) and 1:100 (thin). The position of the 208-nm band is indicated (arrow). B. Comparison of the shapes of the P0 peptide isotropic (thick) and OCD (thin) spectra, both at P/L 1:30. C. The MOG peptide. Thick, isotropic; middle, $O C D$ at $P / L$ 1:30; thin, $O C D$ at $P / L$ 1:100. D. The cx32 N-terminal peptide. Linewidths as in $C$. 
Full-length MBP is a problematic target for spectroscopic methods, as it has a tendency to aggregate lipid vesicles in solution, leading to high turbidity and light scattering. By optimizing the protein-lipid ratios, it has been possible to measure CD spectra from MBP bound to vesicles ${ }^{34}$. Here, we explored further conditions for using SRCD spectroscopy and bicelles and membrane mimics. Turbidity of the MBP samples was not an issue with bicelles, and high-quality spectra could easily be measured (Figure 5A). A significant conformational change towards a helical state was observed with two different bicelle compositions, while increasing salt concentration or molecular crowding induced by polyethylene glycol had little effect (Figure 5B). The negatively charged DMPA/DPC bicelles induced even more helical folding than DMPC/DPC, in line with earlier results on the preference of MBP for negatively charged membranes ${ }^{34}$. Some $\beta$ structure was also apparent in the spectral deconvolutions (Figure 5B). 


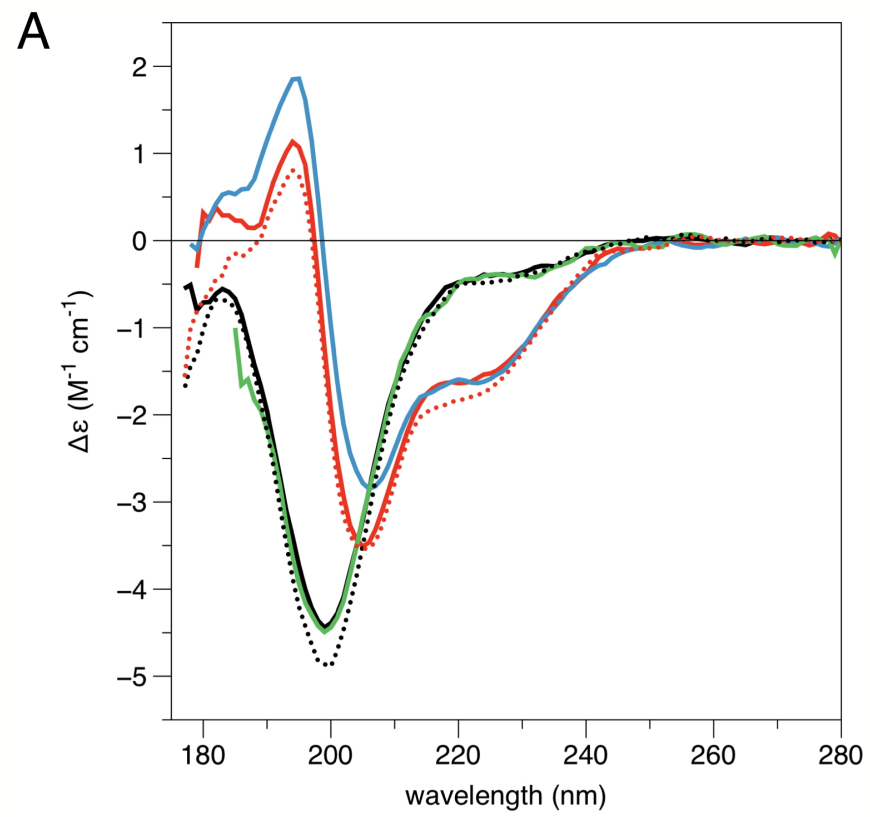

B

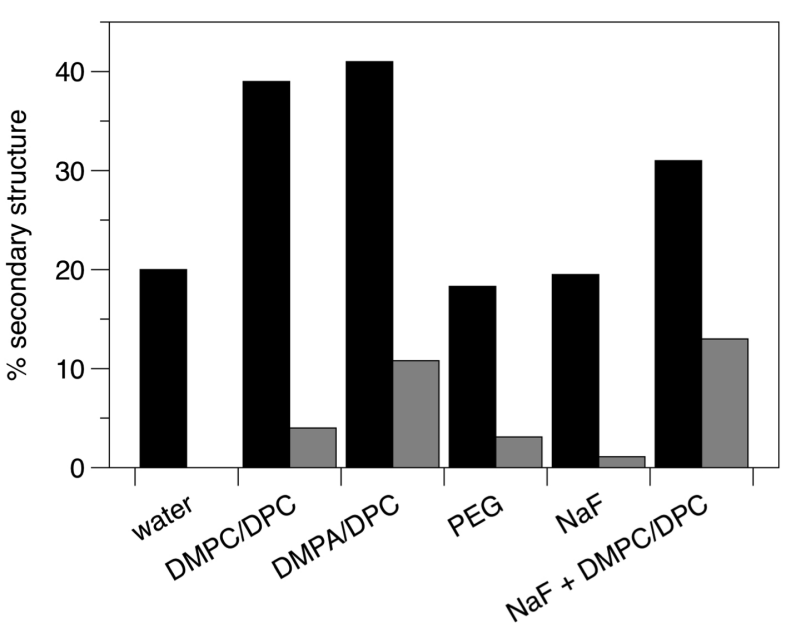

Figure 5. SRCD analysis of full-length mouse 18.5-kDa MBP Cl isoform in various conditions. A. SRCD spectra. No additives, black; 0.25 M NaF, black dotted; 4\% PEG 20000, green; DMPC/DPC bicelles, red; DMPC/DPC + $0.15 \mathrm{M} \mathrm{NaF}$, red dotted; DMPA/DPC bicelles, blue. B. Secondary structure deconvolution. $\alpha$-helix, black; $\beta$-strand, gray.

Temperature scans in DMPC/DPC between $10-35^{\circ} \mathrm{C}$ showed very little variation in the spectra (data not shown); assuming a phase transition of DMPC at $+23^{\circ} \mathrm{C}$, this indicates $\mathrm{MBP}$ conformation is not much affected by the lipid phase. In DMPA/DPC, a denaturing temperature scan up to $+80^{\circ} \mathrm{C}$ was also done, but the only observation was a gradual decrease 
of CD intensity, without moving peak positions (data not shown). This indicates sample aggregation, but no unfolding of the helical structures.

\section{Discussion}

The studies presented here provide important new insights into the membrane interactions of myelin proteins. This information will help in understanding the mechanisms of myelin protein insertion into membranes, as well as the formation of very stable membrane multilayers in the vertebrate nervous system. Specific conclusions for each studied myelin protein are presented below.

\section{Myelin basic protein}

MBP is the second-most abundant myelin protein in the CNS after proteolipid protein (PLP) and constitutes around $30 \%$ of the total myelin protein. It is also present in the PNS at a lower abundance. Post-translational modifications (PTMs) and alternative splicing of MBP result in a number of different size and charge isoforms. The major size isoform is the $18.5-\mathrm{kDa}$ form, which is peripherally membrane-associated. Amongst its charge isomers, $\mathrm{C} 1$ is $\mathrm{N}$-terminally acylated, partially methylated and, thus, the least modified form of MBP. C8 is a result of deimination of arginine to citrulline, a post-translational modification observed in aggressive multiple sclerosis (MS) ${ }^{35-37}$. MBP is a major autoantigen in MS and animal models of autoimmune neurological disorders ${ }^{38}$. MBP is intrinsically unstructured in aqueous solution 34, 39-41; however, it gains significant secondary structure in the presence of certain membrane mimics such as micelles of different detergents ${ }^{34,42,43}$. MBP is one of the most extensively studied myelin molecules, and its membrane-binding segments have been comprehensively 
characterized. Both of the MBP regions represented by the peptides in this study are targets of several reported PTMs, including phosphorylation ${ }^{44,45}$. It is highly likely that such modifications will affect the interactions of MBP with membrane surfaces.

MBP has been extensively studied with regard to its membrane interactions. Various techniques have also been used to characterize the segments represented by the peptides in the present study ${ }^{7,33,43,46-50}$. Three main membrane-anchoring segments have been identified in MBP: close to the $\mathrm{N}$ terminus, in the middle, and close to the $\mathrm{C}$ terminus ${ }^{49}$. The latter two have also been characterized as calmodulin-binding sites ${ }^{7,31,32}$, and it is possible that calmodulin binding can regulate MBP binding to membranes ${ }^{34}$. Another calmodulin-binding site has recently been observed in the N-terminal half of $\mathrm{MBP}^{51}$, but this site has not been characterized in detail yet. The multiple interactions of MBP, as an intrisically unstructured protein, suggest it has 'moonlighting' properties ${ }^{52}$.

The central region, which is also a major autoimmune epitope ${ }^{53}$, is assumed to bind to the membrane in a tilted state, which can become aligned more parallel to the membrane surface e.g. upon phosphorylation ${ }^{33,50,54}$. Here, the two peptides MBP1 and MBP8p correspond to the native and phosphorylated variants of this motif. Both peptides folded helically in membrane-mimicking environments, and also gave a good signal in OCD experiments. The OCD spectrum of the non-phosphorylated peptide suggests a helix alignment that is highly tilted with respect to the plane of the membrane. However, the fact that the band at $208 \mathrm{~nm}$ is still present, indicates the orientation is not fully upright but rather tilted. The conformation of the phosphorylated peptide in OCD was different, and possibly contained a large fraction of $\beta$ structure (which could indicate aggregation). Quite high tilt angles have been reported before for this region in MD simulations, while phosphorylated variants have been suggested to be aligned more parallel to the membrane surface plane ${ }^{33,50}$. We believe that the OCD spectrum of MBP1 corresponds to the conformation of the non-phosphorylated peptides seen in MD simulations, where the central helix of MBP binds to membranes in a significantly 
tilted orientation. At a lower peptide concentration, the spectrum indicated an orientation with a smaller tilt angle, i.e. possibly with a less deep penetration into the membrane. These results suggest that the tilt angle of the peptide increases upon peptide crowding on the membrane, or co-operative effects at increasing concentrations.

Full-length MBP has been the subject of a number of spectroscopic studies in membranous environments ${ }^{3-7}$; however, the turbidity of MBP-lipid complexes, containing semi-solid assemblies, is often a limiting factor for CD spectroscopy. Overcoming sample turbidity would increase the scope of CD spectroscopy, allowing high-quality, high-throughput SRCD data collection from membrane proteins using modern synchrotron sources. This would allow rapid screening of e.g. lipid compositions and mutated protein variants. DPC and TFE have been suggested to be functional mimics of bilayers for MBP ${ }^{46,48}$. Here, we have characterized MBP in lipid-detergent bicelles, overcoming the turbidity issues. The results indicate that MBP binds to the bicelles, and forms significant amounts of secondary structure. The SRCD line shape of the bicelle sample closely resembles that measured from slightly turbid MBPvesicle samples ${ }^{34}$ obtained after careful titration of the protein:lipid ratio. The bicelle system should be more flexible in terms of experimental possibilities in CD spectroscopy, especially at high protein concentrations. At the same time, it resembles a natural membrane better than micelles or organic solvents do. The bicellar system used here will be important in further CD spectroscopic studies on myelin protein conformation in membranes, since many of them are known or expected to bind membranes together ${ }^{25,55,56}$ and thereby cause precipitation and turbidity in the sample, when mixed with phospholipid vesicles. The possibilities of using bicelles to form stacked membranes containing myelin proteins for various applications are currently being explored in our laboratory. 


\section{Other myelin proteins}

The myelin protein P0 is a glycosylated integral membrane protein, found most abundantly in PNS myelin. It constitutes over 50\% of PNS myelin protein. P0 contains an immunoglobulinlike extracellular domain, a transmembrane domain and a short cytoplasmic tail that has no homology to other proteins. P0 has been found to be adhesive at both extracellular and cytoplasmic surfaces of the myelin sheath ${ }^{57}$. The acylated cysteine residue at the start of the cytoplasmic domain ${ }^{58}$ could possibly function as an additional membrane-binding site. Our comparison of isotropic and oriented $\mathrm{CD}$ spectra surprisingly indicates no preferred orientation for the peptide in the macroscopically oriented sample. The peptide also has a rather low helix content when bound to membranes and detergents, indicating it may not have a strong helical propensity and is simply anchored to the membrane through the hydrophobic modification on its Cys residue.

MOG is an integral membrane protein on the outermost lamellae of mature CNS myelin and on the surface of oligodendrocytes. It is a quantitatively minor protein of the myelin sheath and an important autoantigen for primary demyelination in MS ${ }^{59}$ and experimental autoimmune encephalomyelitis ${ }^{60}$. Its extracellular and transmembrane domains are structurally homologous to those of P0. Its C-terminal hydrophobic domain interacts with the plasma membrane, while the N-terminal hydrophobic domain spans the lipid bilayer ${ }^{61}$. The segment studied here represents the very $\mathrm{C}$ terminus of the $20.5-\mathrm{kDa}$ isoform. Our data show that this peptide folds into a helical conformation upon membrane binding, and OCD data suggest an orientation along the membrane surface. This is well in line with the helical wheel projection (Supplementary Figure 1), which shows an amphipathic helix with a high hydrophobic moment. Thus, the $\mathrm{C}$ terminus may function as a membrane anchor on the cytosolic side of MOG. 
Connexin32, also known as gap junction $\beta 1$ protein (GJB1), is a member of the connexin family, which includes proteins that form intracellular channels or gap junctions to establish a low-resistance pathway for intracellular communication in vertebrates ${ }^{62,63}$. $\mathrm{Cx} 32$ is expressed both in the CNS and PNS, and it is highly conserved across mammalian species. Mutations in cx32 cause X-linked Charcot-Marie-Tooth disease (CMTX) ${ }^{64}$; currently, more than 400 disease-causing mutations are known ${ }^{65,66}$. The segment studied here was the N-terminal tail of cx32, assumed to correspond to a short cytoplasmic domain. Our SRCD data clearly indicate that the $\operatorname{cx} 32 \mathrm{~N}$ terminus folds into a helical conformation under membranemimicking conditions. Furthermore, it binds to oriented membranes in a slightly tilted state, as evidenced by OCD spectra. The helical wheel projection of this segment indicates a propensity for amphipathic helix formation; hence, we suggest that the segment represented by this peptide may, in fact, bind to the membrane surface instead of being a cytoplasmic disordered tail. A number of mutations are known in this segment that cause CMTX; these are shown in Figure 6. At least some of them can easily be envisaged to affect the membrane association of the peptide. How the membrane-bound $\mathrm{N}$ terminus affects the assembly and function of cx32 in gap junctions, remains to be elucidated.

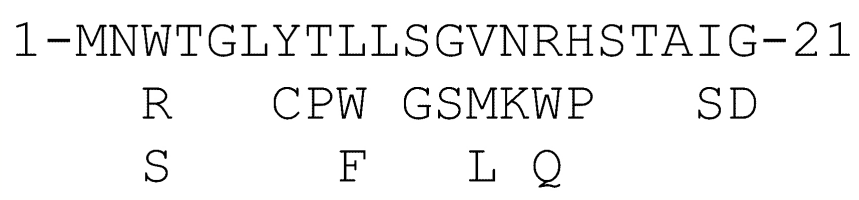

Figure 6. Known CMTX mutations in the cx32 $N$ terminus represented by the studied peptide.

\section{Concluding remarks}


We have provided novel data on the folding and orientation of membrane-associating segments from several important myelin proteins. These studies were carried out mainly with short peptides, and while our data provide novel information on myelin protein-membrane interactions, the results are unlikely to fully represent the corresponding phenomena in the full-length proteins, as has been also shown for $\mathrm{MBP}^{6,51}$. In addition, the combined use of other biophysical/structural biology methods to study the same system is mandatory for a complete picture. Specifically related to the current study, membrane binding by MBP has been studied extensively with different methodologies, and while common trends are clear, also differences in the structural details upon membrane binding have become evident, when using different methods ${ }^{3}$. In the future, it will be important to further extend high-quality SRCD and OCD methods, preferably in combination with each other and other state-of-theart methods, to study full-length myelin proteins in the context of multilayered membranes, which is a close approximation of their natural biological environment. We have already initiated such studies using the myelin peripheral membrane protein $\mathrm{P} 2$, which is also the first $\beta$-structured full-length protein to be studied using OCD. Combined with complementary approaches, the future goal will be to obtain high-resolution data on myelin protein organization within multilayered myelin membranes, which will help to understand nervous system development and function, as well as the etiology of demyelinating neurodegenerative diseases. 


\section{Acknowledgements}

We wish to thank Chaozhan Wang for MBP purification, and ISA for providing generous SRCD beamtime. We acknowledge the Synchrotron Light Source ANKA for provision of SRCD beamtime at the UV-CD12 beamline and Bianca Posselt for technical assistance in the OCD sample preparation. This study has been supported by grants from the Academy of Finland, Sigrid Jusélius Foundation, BMBF, and the Research and Science Foundation Hamburg.

\section{Supporting Information Available}

Supplementary Figure 1 contains the helical wheel projection analysis of the peptides used in this study. This information is available free of charge via the Internet at http://pubs.acs.org. 


\section{References}

(1) Han, H.; Myllykoski, M.; Ruskamo, S.; Wang, C.; Kursula, P. Myelin-Specific Proteins: A Structurally Diverse Group of Membrane-Interacting Molecules. Biofactors 2013, $39,233-241$.

(2) Kursula, P. Structural Properties of Proteins Specific to the Myelin Sheath. Amino Acids 2008, 34, 175-185.

(3) Ahmed, M. A.; Bamm, V. V.; Harauz, G.; Ladizhansky, V. Solid-State NMR Spectroscopy of Membrane-Associated Myelin Basic Protein--Conformation and Dynamics of an Immunodominant Epitope. Biophys. J. 2010, 99, 1247-1255.

(4) Smith, G. S.; Chen, L.; Bamm, V. V.; Dutcher, J. R.; Harauz, G. The Interaction of Zinc With Membrane-Associated $18.5 \mathrm{kDa}$ Myelin Basic Protein: An Attenuated Total Reflectance-Fourier Transform Infrared Spectroscopic Study. Amino Acids 2010, 39, 739-750.

(5) Polverini, E.; Boggs, J. M.; Bates, I. R.; Harauz, G.; Cavatorta, P. Electron Paramagnetic Resonance Spectroscopy and Molecular Modelling of the Interaction of Myelin Basic Protein (MBP) With Calmodulin (CaM)-Diversity and Conformational Adaptability of Mbp Cam-Targets. J. Struct. Biol. 2004, 148, 353-369.

(6) Musse, A. A.; Boggs, J. M.; Harauz, G. Deimination of Membrane-Bound Myelin Basic Protein in Multiple Sclerosis Exposes an Immunodominant Epitope. Proc. Natl Acad. Sci. USA 2006, 103, 4422-4427.

(7) Homchaudhuri, L.; De Avila, M.; Nilsson, S. B.; Bessonov, K.; Smith, G. S.; Bamm, V. V.; Musse, A. A.; Harauz, G.; Boggs, J. M. Secondary Structure and Solvent Accessibility of a Calmodulin-Binding C-Terminal Segment of Membrane-Associated Myelin Basic Protein. Biochemistry 2010, 49, 8955-8966.

(8) Bürck, J.; Roth, S.; Wadhwani, P.; Afonin, S.; Kanithasen, N.; Strandberg, E.; Ulrich, A. S. Conformation and Membrane Orientation of Amphiphilic Helical Peptides By Oriented Circular Dichroism. Biophys. J. 2008, 95, 3872-3881.

(9) Heinzmann, R.; Grage, S. L.; Schalck, C.; Bürck, J.; Banoczi, Z.; Toke, O.; Ulrich, A. S. A Kinked Antimicrobial Peptide From Bombina Maxima. II. Behavior in Phospholipid Bilayers. Eur. Biophys. J. 2011, 40, 463-470.

(10) Klein, M. J.; Grage, S. L.; Muhle-Goll, C.; Bürck, J.; Afonin, S.; Ulrich, A. S. Structure Analysis of the Membrane-Bound PhoD Signal Peptide of the Tat Translocase Shows an N-Terminal Amphiphilic Helix. Biochim. Biophys. Acta 2012, 1818, 3025-3031.

(11) Muhle-Goll, C.; Hoffmann, S.; Afonin, S.; Grage, S. L.; Polyansky, A. A.; Windisch, D.; Zeitler, M.; Bürck, J.; Ulrich, A. S. Hydrophobic Matching Controls the Tilt and Stability of the Dimeric Platelet-Derived Growth Factor Receptor (PDGFR) Beta Transmembrane Segment. J. Biol. Chem. 2012, 287, 26178-26186.

(12) Olah, G. A.; Huang, H. W. Circular Dichroism of Oriented $\alpha$-Helices. II. Electric Field Oriented Polypeptides. J. Chem. Phys. 1988, 89, 6956-6962.

(13) Steinbrecher, T.; Prock, S.; Reichert, J.; Wadhwani, P.; Zimpfer, B.; Bürck, J.; Berditsch, M.; Elstner, M.; Ulrich, A. S. Peptide-Lipid Interactions of the Stress-Response Peptide TisB That Induces Bacterial Persistence. Biophys. J. 2012, 103, 1460-1469.

(14) Wimley, W. C.; White, S. H. Designing Transmembrane $\alpha$-Helices That Insert Spontaneously. Biochemistry 2000, 39, 4432-4442. 
(15) Windisch, D.; Hoffmann, S.; Afonin, S.; Vollmer, S.; Benamira, S.; Langer, B.; Bürck, J.; Muhle-Goll, C.; Ulrich, A. S. Structural Role of the Conserved Cysteines in the Dimerization of the Viral Transmembrane Oncoprotein E5. Biophys. J. 2010, 99, 1764-1772.

(16) Wu, Y.; Huang, H. W.; Olah, G. A. Method of Oriented Circular Dichroism. Biophys. J. 1990, 57, 797-806.

(17) Lange, C.; Muller, S. D.; Walther, T. H.; Bürck, J.; Ulrich, A. S. Structure Analysis of the Protein Translocating Channel TatA in Membranes Using a Multi-Construct Approach. Biochim. Biophys. Acta 2007, 1768, 2627-2634.

(18) Nolandt, O. V.; Walther, T. H.; Roth, S.; Bürck, J.; Ulrich, A. S. Structure Analysis of the Membrane Protein TatC(D) From the Tat System of B. Subtilis By Circular Dichroism. Biochim. Biophys. Acta 2009, 1788, 2238-2244.

(19) Heller, W. T.; Waring, A. J.; Lehrer, R. I.; Huang, H. W. Multiple States of Beta-Sheet Peptide Protegrin in Lipid Bilayers. Biochemistry 1998, 37, 17331-17338.

(20) Wadhwani, P.; Strandberg, E.; Heidenreich, N.; Bürck, J.; Fanghanel, S.; Ulrich, A. S. Self-Assembly of Flexible Beta-Strands Into Immobile Amyloid-Like Beta-Sheets in Membranes as Revealed By Solid-State 19F NMR. J. Am. Chem. Soc. 2012, 134, 6512-6515.

(21) Ruskamo, S.; Yadav, R. P.; Sharma, S.; Lehtimäki, M.; Laulumaa, S.; Aggarwal, S.; Simons, M.; Bürck, J.; Ulrich, A. S.; Juffer, A. H. et al. Atomic-Resolution View Into Structure-Function Relationships of the Human Myelin Peripheral Membrane Protein P2. Acta Cryst. D 2013, in press.

(22) Myllykoski, M.; Baumgärtel, P.; Kursula, P. Conformations of Peptides Derived From Myelin-Specific Proteins in Membrane-Mimetic Conditions Probed By Synchrotron Radiation CD Spectroscopy. Amino Acids 2012, 42, 1467-1474.

(23) Sapay, N.; Guermeur, Y.; Deleage, G. Prediction of Amphipathic in-Plane Membrane Anchors in Monotopic Proteins Using a SVM Classifier. BMC Bioinformatics 2006, 7, 255.

(24) Bates, I. R.; Matharu, P.; Ishiyama, N.; Rochon, D.; Wood, D. D.; Polverini, E.; Moscarello, M. A.; Viner, N. J.; Harauz, G. Characterization of a Recombinant Murine 18.5kDa Myelin Basic Protein. Protein Expr. Purif. 2000, 20, 285-299.

(25) Suresh, S.; Wang, C.; Nanekar, R.; Kursula, P.; Edwardson, J. M. Myelin Basic Protein and Myelin Protein 2 Act Synergistically to Cause Stacking of Lipid Bilayers. Biochemistry 2010, 49, 3456-3463.

(26) Lees, J. G.; Smith, B. R.; Wien, F.; Miles, A. J.; Wallace, B. A. CDtool-an Integrated Software Package for Circular Dichroism Spectroscopic Data Processing, Analysis, and Archiving. Anal. Biochem. 2004, 332, 285-289.

(27) Greenfield, N.; Fasman, G. D. Computed Circular Dichroism Spectra for the Evaluation of Protein Conformation. Biochemistry 1969, 8, 4108-4116.

(28) Whitmore, L.; Woollett, B.; Miles, A. J.; Klose, D. P.; Janes, R. W.; Wallace, B. A. PCDDB: The Protein Circular Dichroism Data Bank, a Repository for Circular Dichroism Spectral and Metadata. Nucleic Acids Res. 2011, 39, D480-486.

(29) Greenfield, N. J. Using Circular Dichroism Spectra to Estimate Protein Secondary Structure. Nat. Protoc. 2006, 1, 2876-2890.

(30) Chen, F. Y.; Lee, M. T.; Huang, H. W. Sigmoidal Concentration Dependence of Antimicrobial Peptide Activities: A Case Study on Alamethicin. Biophys. J. 2002, 82, 908-914. 
(31) Majava, V.; Petoukhov, M. V.; Hayashi, N.; Pirilä, P.; Svergun, D. I.; Kursula, P. Interaction Between the C-Terminal Region of Human Myelin Basic Protein and Calmodulin: Analysis of Complex Formation and Solution Structure. BMC Struct. Biol. 2008, 8, 10.

(32) Majava, V.; Wang, C.; Myllykoski, M.; Kangas, S. M.; Kang, S. U.; Hayashi, N.; Baumgärtel, P.; Heape, A. M.; Lubec, G.; Kursula, P. Structural Analysis of the Complex Between Calmodulin and Full-Length Myelin Basic Protein, an Intrinsically Disordered Molecule. Amino Acids 2010, 39, 59-71.

(33) Polverini, E.; Coll, E. P.; Tieleman, D. P.; Harauz, G. Conformational Choreography of a Molecular Switch Region in Myelin Basic Protein--Molecular Dynamics Shows Induced Folding and Secondary Structure Type Conversion Upon Threonyl Phosphorylation in Both Aqueous and Membrane-Associated Environments. Biochim. Biophys. Acta 2011, 1808, 674-683.

(34) Wang, C.; Neugebauer, U.; Bürck, J.; Myllykoski, M.; Baumgärtel, P.; Popp, J.; Kursula, P. Charge Isomers of Myelin Basic Protein: Structure and Interactions With Membranes, Nucleotide Analogues, and Calmodulin. PLoS ONE 2011, 6, e19915.

(35) Beniac, D. R.; Wood, D. D.; Palaniyar, N.; Ottensmeyer, F. P.; Moscarello, M. A.; Harauz, G. Marburg's Variant of Multiple Sclerosis Correlates With a Less Compact Structure of Myelin Basic Protein. Mol. Cell. Biol. Res. Commun. 1999, 1, 48-51.

(36) Moscarello, M. A.; Wood, D. D.; Ackerley, C.; Boulias, C. Myelin in Multiple Sclerosis is Developmentally Immature. J. Clin. Invest. 1994, 94, 146-154.

(37) Wood, D. D.; Moscarello, M. A. The Isolation, Characterization, and LipidAggregating Properties of a Citrulline Containing Myelin Basic Protein. J. Biol. Chem. 1989, 264, 5121-5127.

(38) Lutton, J. D.; Winston, R.; Rodman, T. C. Multiple Sclerosis: Etiological Mechanisms and Future Directions. Exp. Biol. Med. 2004, 229, 12-20.

(39) Harauz, G.; Ishiyama, N.; Hill, C. M.; Bates, I. R.; Libich, D. S.; Fares, C. Myelin Basic Protein-Diverse Conformational States of an Intrinsically Unstructured Protein and Its Roles in Myelin Assembly and Multiple Sclerosis. Micron 2004, 35, 503-542.

(40) Krigbaum, W. R.; Hsu, T. S. Molecular Conformation of Bovine A1 Basic Protein, a Coiling Macromolecule in Aqueous Solution. Biochemistry 1975, 14, 2542-2546.

(41) Polverini, E.; Fasano, A.; Zito, F.; Riccio, P.; Cavatorta, P. Conformation of Bovine Myelin Basic Protein Purified With Bound Lipids. Eur. Biophys. J. 1999, 28, 351-355.

(42) Bamm, V. V.; Ahmed, M. A.; Harauz, G. Interaction of Myelin Basic Protein With Actin in the Presence of Dodecylphosphocholine Micelles. Biochemistry 2010, 49, 6903-6915.

(43) Libich, D. S.; Harauz, G. Solution Nmr and Cd Spectroscopy of an Intrinsically Disordered, Peripheral Membrane Protein: Evaluation of Aqueous and Membrane-Mimetic Solvent Conditions for Studying the Conformational Adaptability of the $18.5 \mathrm{kDa}$ Isoform of Myelin Basic Protein (MBP). Eur. Biophys. J. 2008, 37, 1015-1029.

(44) Kim, J. K.; Mastronardi, F. G.; Wood, D. D.; Lubman, D. M.; Zand, R.; Moscarello, M. A. Multiple Sclerosis: An Important Role for Post-Translational Modifications of Myelin Basic Protein in Pathogenesis. Mol. Cell. Proteomics 2003, 2, 453-462.

(45) Cruz, T. F.; Wood, D. D.; Moscarello, M. A. The Identification of Threonine-95 as the Major Site of Glycosylation in Normal Human Myelin Basic Protein. Biochem. J. 1984, 220, 849-852. 
(46) Ahmed, M. A.; De Avila, M.; Polverini, E.; Bessonov, K.; Bamm, V. V.; Harauz, G. Solution Nuclear Magnetic Resonance Structure and Molecular Dynamics Simulations of a Murine $18.5 \mathrm{kDa}$ Myelin Basic Protein Segment (S72-S107) in Association With Dodecylphosphocholine Micelles. Biochemistry 2012, 51, 7475-7487.

(47) Bates, I. R.; Boggs, J. M.; Feix, J. B.; Harauz, G. Membrane-Anchoring and Charge Effects in the Interaction of Myelin Basic Protein With Lipid Bilayers Studied By SiteDirected Spin Labeling. J. Biol. Chem. 2003, 278, 29041-29047.

(48) Fares, C.; Libich, D. S.; Harauz, G. Solution Nmr Structure of an Immunodominant Epitope of Myelin Basic Protein. Conformational Dependence on Environment of an Intrinsically Unstructured Protein. FEBS J. 2006, 273, 601-614.

(49) Libich, D. S.; Harauz, G. Backbone Dynamics of the $18.5 \mathrm{kDa}$ Isoform of Myelin Basic Protein Reveals Transient Alpha-Helices and a Calmodulin-Binding Site. Biophys. J. 2008, 94, 4847-4866.

(50) Vassall, K. A.; Bessonov, K.; De Avila, M.; Polverini, E.; Harauz, G. The Effects of Threonine Phosphorylation on the Stability and Dynamics of the Central Molecular Switch Region of 18.5-kDa Myelin Basic Protein. PLOS ONE 2013, 8, e68175.

(51) Bamm, V. V.; De Avila, M.; Smith, G. S.; Ahmed, M. A.; Harauz, G. Structured Functional Domains of Myelin Basic Protein: Cross Talk Between Actin Polymerization and $\mathrm{Ca}(2+)$-Dependent Calmodulin Interaction. Biophys. J. 2011, 101, 1248-1256.

(52) Tompa, P.; Szasz, C.; Buday, L. Structural Disorder Throws New Light on Moonlighting. Trends Biochem. Sci. 2005, 30, 484-489.

(53) Warren, K. G.; Catz, I.; Steinman, L. Fine Specificity of the Antibody Response to Myelin Basic Protein in the Central Nervous System in Multiple Sclerosis: The Minimal BCell Epitope and a Model of Its Features. Proc. Natl Acad. Sci. USA 1995, 92, 11061-11065.

(54) Bates, I. R.; Feix, J. B.; Boggs, J. M.; Harauz, G. An Immunodominant Epitope of Myelin Basic Protein is an Amphipathic $\alpha$-Helix. J. Biol. Chem. 2004, 279, 5757-5764.

(55) Majava, V.; Polverini, E.; Mazzini, A.; Nanekar, R.; Knoll, W.; Peters, J.; Natali, F.; Baumgärtel, P.; Kursula, I.; Kursula, P. Structural and Functional Characterization of Human Peripheral Nervous System Myelin Protein P2. PLoS ONE 2010, 5, e10300.

(56) Sedzik, J.; Blaurock, A. E.; Hoechli, M. Reconstituted P2/Myelin-Lipid Multilayers. J. Neurochem. 1985, 45, 844-852.

(57) Eichberg, J. Myelin P0: New Knowledge and New Roles. Neurochem. Res. 2002, 27, 1331-1340.

(58) Bizzozero, O. A.; Fridal, K.; Pastuszyn, A. Identification of the Palmitoylation Site in Rat Myelin P0 Glycoprotein. J. Neurochem. 1994, 62, 1163-1171.

(59) Iglesias, A.; Bauer, J.; Litzenburger, T.; Schubart, A.; Linington, C. T- and B-Cell Responses to Myelin Oligodendrocyte Glycoprotein in Experimental Autoimmune Encephalomyelitis and Multiple Sclerosis. Glia 2001, 36, 220-234.

(60) Mayer, M. C.; Meinl, E. Glycoproteins as Targets of Autoantibodies in CNS Inflammation: MOG and More. Ther. Adv. Neurol. Disord. 2012, 5, 147-159.

(61) Kroepfl, J. F.; Viise, L. R.; Charron, A. J.; Linington, C.; Gardinier, M. V. Investigation of Myelin/Oligodendrocyte Glycoprotein Membrane Topology. J. Neurochem. 1996, 67, 2219-2222.

(62) Kumar, N. M.; Gilula, N. B. Cloning and Characterization of Human and Rat Liver Cdnas Coding for a Gap Junction Protein. J. Cell Biol. 1986, 103, 767-776. 
(63) Ri, Y.; Ballesteros, J. A.; Abrams, C. K.; Oh, S.; Verselis, V. K.; Weinstein, H.; Bargiello, T. A. The Role of a Conserved Proline Residue in Mediating Conformational Changes Associated With Voltage Gating of Cx32 Gap Junctions. Biophys. J. 1999, 76, 2887-2898.

(64) Bergoffen, J.; Scherer, S. S.; Wang, S.; Scott, M. O.; Bone, L. J.; Paul, D. L.; Chen, K.; Lensch, M. W.; Chance, P. F.; Fischbeck, K. H. Connexin Mutations in X-Linked Charcot-Marie-Tooth Disease. Science 1993, 262, 2039-2042.

(65) Kleopa, K. A.; Abrams, C. K.; Scherer, S. S. How Do Mutations in GJB1 Cause XLinked Charcot-Marie-Tooth Disease? Brain Res. 2012, 1487, 198-205.

(66) Yum, S. W.; Kleopa, K. A.; Shumas, S.; Scherer, S. S. Diverse Trafficking Abnormalities of Connexin32 Mutants Causing CMTX. Neurobiol. Disease 2002, 11, 43-52. 
Table of Contents Image

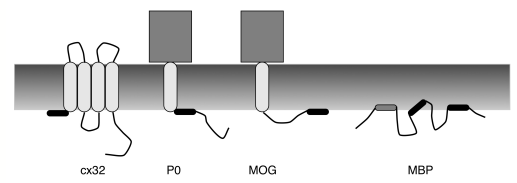

